\title{
Thin-Film Composite Pressure Retarded Osmosis Membranes for Sustainable Power Generation from Salinity Gradients
}

\author{
Ngai Yin Yip, Alberto Tiraferri, William A. Phillip, Jessica D. Schiffman, Laura A. Hoover, Yu Chang Kim, and \\ Menachem Elimelech*
}

Department of Chemical and Environmental Engineering, Yale University, New Haven, Connecticut 06520-8286, United States

Supporting Information

ABSTRACT: Pressure retarded osmosis has the potential to produce renewable energy from natural salinity gradients. This work presents the fabrication of thin-film composite membranes customized for high performance in pressure retarded osmosis. We also present the development of a theoretical model to predict the water flux in pressure retarded osmosis, from which we can predict the power density that can be achieved by a membrane. The model is the first to incorporate external concentration polarization, a performance limiting
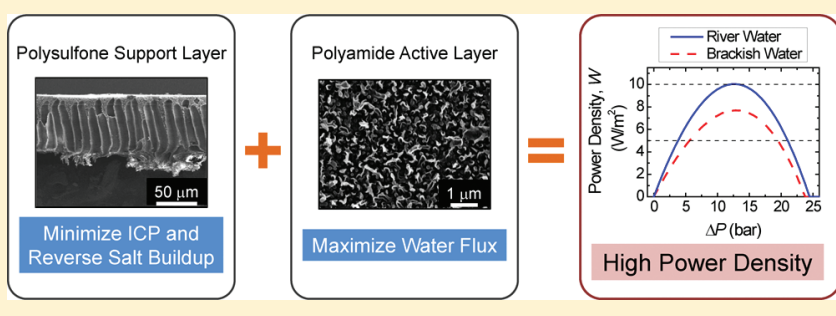
phenomenon that becomes significant for high-performance membranes. The fabricated membranes consist of a selective polyamide layer formed by interfacial polymerization on top of a polysulfone support layer made by phase separation. The highly porous support layer (structural parameter $S=349 \mu \mathrm{m}$ ), which minimizes internal concentration polarization, allows the transport properties of the active layer to be customized to enhance PRO performance. It is shown that a hand-cast membrane that balances permeability and selectivity $\left(A=5.81 \mathrm{~L} \mathrm{~m}^{-2} \mathrm{~h}^{-1} \mathrm{bar}^{-1}, B=0.88 \mathrm{~L} \mathrm{~m}^{-2} \mathrm{~h}^{-1}\right)$ is projected to achieve the highest potential peak power density of $10.0 \mathrm{~W} / \mathrm{m}^{2}$ for a river water feed solution and seawater draw solution. The outstanding performance of this membrane is attributed to the high water permeability of the active layer, coupled with a moderate salt permeability and the ability of the support layer to suppress the undesirable accumulation of leaked salt in the porous support. Membranes with greater selectivity (i.e., lower salt permeability, $\left.B=0.16 \mathrm{~L} \mathrm{~m}^{-2} \mathrm{~h}^{-1}\right)$ suffered from a lower water permeability $\left(A=1.74 \mathrm{~L} \mathrm{~m}^{-2} \mathrm{~h}^{-1}\right.$ bar $\left.^{-1}\right)$ and would yield a lower peak power density of $6.1 \mathrm{~W} / \mathrm{m}^{2}$, while membranes with a higher permeability and lower selectivity $\left(A=7.55 \mathrm{~L} \mathrm{~m}^{-2} \mathrm{~h}^{-1} \mathrm{bar}^{-1}, B=\right.$ $5.45 \mathrm{~L} \mathrm{~m}^{-2} \mathrm{~h}^{-1}$ ) performed poorly due to severe reverse salt permeation, resulting in a similar projected peak power density of $6.1 \mathrm{~W} / \mathrm{m}^{2}$.

\section{INTRODUCTION}

Current global energy demand far exceeds our capacity for sustainable production. Prolonged reliance on fossil fuels, which provide the bulk of our energy, is untenable because of the emission of greenhouse gases and air pollutants. ${ }^{1}$ Although the development of a broad range of alternative energy technologies is making progress in increasing sustainable energy production, we still depend heavily on fossil fuels to meet our needs. To satisfy the energy requirements of the present and future, existing alternative energy production technologies must be advanced beyond their current limitations, ${ }^{1}$ and additional sources of sustainable energy must be tapped.

Pressure retarded osmosis (PRO) holds the potential to produce renewable energy from natural and anthropogenic salinity gradients. ${ }^{2}$ PRO exploits the osmotic pressure difference that develops when a semipermeable membrane separates two solutions of different concentrations. As a result of the osmotic pressure difference, water permeates from the dilute "feed solution" into the more concentrated "draw solution". A hydraulic pressure less than the osmotic pressure difference is applied on the draw solution, and a hydroturbine extracts work from the expanding draw solution volume.
Input streams for PRO are available in both natural and industrial settings. Natural salinity gradients, for example those arising from the mixing of freshwater rivers flowing into oceans, have the potential to produce $1650 \mathrm{TWh} /$ year..$^{3}$ Additionally, PRO can use anthropogenic waste streams, such as concentrated brine from a desalination plant, ${ }^{4}$ as draw solutions. A closed-loop version of PRO, the osmotic heat engine, has also been proposed. This process uses low grade heat to power the separation and regeneration of its thermolytic draw solution of dissolved ammonia and carbon dioxide gases. The conversion of low grade heat that would otherwise be discarded into useable electricity creates a net benefit. ${ }^{5}$ The continuous availability of both natural water resources and anthropogenic waste streams indicates that PRO systems will not suffer from the intermittency problems that plague some other renewable energy generation methods.

Despite its potential, the development of PRO has been hindered by the lack of a suitable membrane. The bulky support

Received: December 23, 2010

Accepted: April 4, 2011

Revised: April 2, 2011

Published: April 14, 2011 
layers of reverse osmosis ( $\mathrm{RO}$ ) membranes cause severe internal concentration polarization (ICP), which dramatically reduces water flux. ${ }^{6}$ Consequently, these RO membranes achieve only nominal power densities (power produced per membrane area) in PRO operation. A commercial cellulose acetate membrane designed for another osmotically driven membrane process, forward osmosis (FO), experiences relatively less ICP due to its specialized support layer. ${ }^{7,8}$ However, the relatively low intrinsic water permeability of the membrane material restricts the power density it can attain. Furthermore, cellulose acetate membranes can operate only within a $\mathrm{pH}$ range of $4-6,9,10$ therefore limiting their application.

A PRO pilot plant in Norway that was built to demonstrate the technology used cellulose acetate membranes to generate $<0.5$ $\mathrm{W} / \mathrm{m}^{2}{ }^{11}$ This power density is an order of magnitude lower than the power density of $5 \mathrm{~W} / \mathrm{m}^{2}$ required to make this specific installation commercially viable. ${ }^{12}$ To date, no membrane has demonstrated a PRO power density greater than $3.5 \mathrm{~W} / \mathrm{m}^{2}$ using freshwater and seawater. ${ }^{2}$

For power generation by $\mathrm{PRO}$ to be commercially feasible, the gap in membrane performance must be bridged. We have recently developed a high-performance thin-film composite FO membrane. ${ }^{13,14}$ Through control of the fabrication parameters, the support layer was tailored to decrease ICP, thereby increasing water flux. Like FO, PRO requires a membrane that minimizes ICP. However, a key difference between the two processes affords us the opportunity to further customize the active layer. FO is a separation process and requires a highly selective membrane, while PRO exploits the controlled mixing of solutions to generate energy and therefore only needs enough salt rejection to maintain the osmotic driving force. ${ }^{6}$ The constraint of high selectivity that limits water flux in FO through the selectivity-permeability trade-off ${ }^{15}$ is therefore partially relaxed for PRO membranes, and an additional degree of freedom exists in PRO membrane design.

This study demonstrates the fabrication of a customized thinfilm composite membrane that has the potential to achieve a high power density in PRO. Hand-cast thin-film composite PRO membranes with a range of water and salt permeabilities were prepared. Membrane performance was evaluated in PRO configuration using a synthetic seawater draw solution paired with river or brackish water feed solutions. The influence of membrane properties on power density in PRO systems is analyzed and discussed. This experimental and theoretical work aims to provide basic criteria in the design of customized PRO membranes for sustainable power generation by establishing the influence of membrane characteristics on PRO performance.

\section{THEORY}

A schematic of the salt concentration profile across a thin-film composite membrane operating in PRO mode (i.e., active layer facing the draw solution) is shown in Figure 1. Due to the detrimental effects of internal concentration polarization (ICP) within the porous support, salt permeation across the membrane, and external concentration polarization (ECP) in the draw solution, the osmotic driving force is lower than the osmotic pressure difference between the bulk draw and feed solutions. Earlier studies to derive the PRO water flux equation did not take ECP into account. ${ }^{6,8}$ ECP can be significant for high-performance PRO membranes having low membrane structural parameters and high water fluxes. In this section we present the derivation of

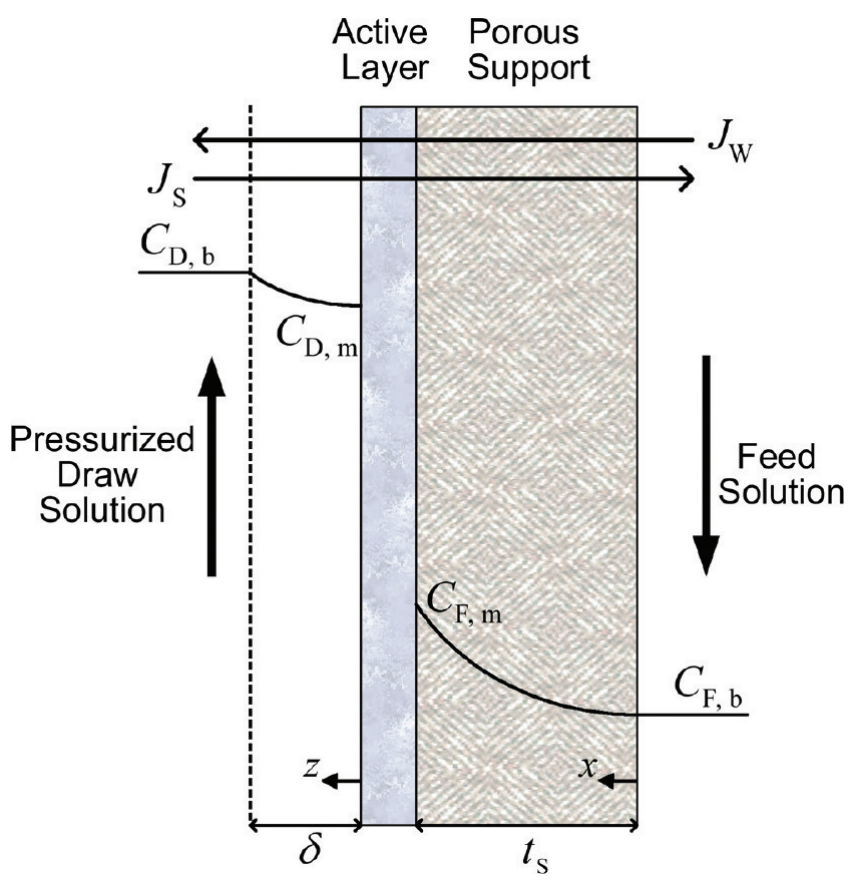

Figure 1. A schematic representation of the salt concentration profile across a thin-film composite membrane in PRO mode at steady state. The feed and draw solutions are introduced to the membrane in crossflow. Dilutive external concentration polarization occurs in the mass transfer boundary layer of the draw solution, reducing the local concentration at the active layer from $C_{\mathrm{D}, \mathrm{b}}$ to $C_{\mathrm{D}, \mathrm{m}}$. Concentrative internal concentration polarization takes place within the porous support, increasing the local concentration at the active-support interface from $C_{\mathrm{F}, \mathrm{b}}$ to $C_{\mathrm{F}, \mathrm{m}}$. Concentrative $\mathrm{ECP}$ in the feed solution is assumed to be negligible. The pressurized draw solution creates a hydraulic pressure drop across the membrane, $\Delta P$, which is lower than the osmotic pressure difference across the membrane.

the complete water flux equation for PRO taking into consideration all the above-mentioned effects.

Water and Salt Fluxes Across the Active Layer. Water flux, $J_{\mathrm{w}}$, across the membrane is given by $^{9}$

$$
J_{\mathrm{w}}=A\left(\Delta \pi_{\mathrm{m}}-\Delta P\right)
$$

where $A$ is the intrinsic water permeability coefficient of the membrane, $\Delta \pi_{\mathrm{m}}$ is the effective osmotic pressure across the active layer, and $\Delta P$ is the applied hydraulic pressure difference across the membrane. Salt permeates across the membrane in the opposite direction of the water flux, from the more concentrated draw solution into the feed solution. The reverse salt flux, $J_{s}$, is described by ${ }^{6,16}$

$$
J_{\mathrm{s}}=B\left(C_{\mathrm{D}, \mathrm{m}}-C_{\mathrm{F}, \mathrm{m}}\right)
$$

where $B$ is the salt permeability coefficient of the membrane active layer and $C_{\mathrm{D}, \mathrm{m}}$ and $C_{\mathrm{F}, \mathrm{m}}$ are the solute concentrations in solution at the active layer interface on the draw and feed sides, respectively.

Mass Transfer in the Porous Support Layer. As water permeates across the membrane, the feed solutes are selectively retained by the semipermeable active layer and build up within the porous support, resulting in ICP. Diffusion works to restore this local concentration to the bulk feed solution concentration but is hindered by the porous support, which acts as an unstirred boundary layer. The salt flux across the porous support is the sum 
of the diffusive component, driven by the salt concentration gradient, and the convective component, arising from the bulk flow of water through the membrane: ${ }^{6}$

$$
J_{\mathrm{s}}=D^{\mathrm{s}} \frac{\mathrm{d} C(x)}{\mathrm{d} x}-J_{\mathrm{w}} C(x)
$$

where $D^{s}$ is the effective diffusion coefficient of the draw solute in the porous support. It can be related to the bulk diffusion coefficient, $D$, by accounting for the porosity, $\varepsilon$, and tortuosity, $\tau$, of the support layer, i.e., $D^{s}=D \varepsilon / \tau .^{16}$

At steady-state, the salt fluxes across the active (eq 2) and support (eq 3 ) layers are equal:

$$
D^{\mathrm{s}} \frac{\mathrm{d} C(x)}{\mathrm{d} x}-J_{\mathrm{w}} C(x)=B\left(C_{\mathrm{D}, \mathrm{m}}-C_{\mathrm{F}, \mathrm{m}}\right)
$$

Integrating eq 4 across the support layer thickness, from the porous layer-feed solution interface, $x=0$, where the salt concentration is $C_{\mathrm{F}, \mathrm{b}}$, to the porous layer-active layer interface, $x=t_{\mathrm{s}}$, where the salt concentration is $C_{\mathrm{F}, \mathrm{m}}$ (Figure 1$)$, yields

$$
C_{\mathrm{F}, \mathrm{m}}=C_{\mathrm{F}, \mathrm{b}} \exp \left(\frac{J_{\mathrm{w}} S}{D}\right)+\frac{B}{J_{\mathrm{w}}}\left(C_{\mathrm{D}, \mathrm{m}}-C_{\mathrm{F}, \mathrm{m}}\right)\left[\exp \left(\frac{J_{w} S}{D}\right)-1\right]
$$

where $S=t_{\mathrm{s}} \tau / \varepsilon$ is the support layer structural parameter. ${ }^{13}$ Note that in the above analysis we do not consider ECP in the feed solution because the support layer thickness is relatively large, thereby dominating concentration polarization.

Equation 5 indicates that the salt concentration at the activesupport interface, $C_{\mathrm{F}, \mathrm{m}}$ is the sum of two terms. The effect of concentrative ICP is described by the first term on the right-hand side, where the bulk feed solution concentration is magnified by a factor of $\exp \left(J_{\mathrm{w}} S / D\right)$. The second term accounts for the increase in salt concentration at the membrane interface due to the reverse permeation of draw solution salt into the porous support.

Mass Transfer in the External Concentration Polarization Layer. As water permeates across the membrane, it dilutes the draw solution at the active layer, resulting in ECP. Similar to ICP, the salt flux within this ECP boundary layer comprises diffusive and convective components: ${ }^{9}$

$$
J_{\mathrm{s}}=D \frac{\mathrm{d} C(z)}{\mathrm{d} z}-J_{\mathrm{w}} C(z)
$$

At steady-state, the salt flux within the ECP boundary layer (eq 6) is equal to the salt flux across the active layer (eq 2). Integrating the resulting equation across the ECP boundary layer from the active layer, $z=0$, where the salt concentration is $C_{\mathrm{D}, \mathrm{m}}$, to the bulk draw solution, $z=\delta$, where the salt concentration is $C_{\mathrm{D}, \mathrm{b}}$, yields

$$
C_{\mathrm{D}, \mathrm{m}}=C_{\mathrm{D}, \mathrm{b}} \exp \left(-\frac{J_{\mathrm{w}}}{k}\right)-\frac{B}{J_{\mathrm{w}}}\left(C_{\mathrm{D}, \mathrm{m}}-C_{\mathrm{F}, \mathrm{m}}\right)\left[1-\exp \left(-\frac{J_{\mathrm{w}}}{k}\right)\right]
$$

where $k=D / \delta$ is the boundary layer mass transfer coefficient. Inspecting eq 7 reveals that $C_{\mathrm{D}, \mathrm{m}}$ is dependent on two terms. The first term describes the bulk draw concentration, $C_{\mathrm{D}, \mathrm{b}}$, corrected for ECP by the factor $\exp \left(-J_{\mathrm{w}} / k\right)$, while the second term represents the loss in solute concentration due to salt leakage across the active layer.

Water Flux in PRO with ICP, ECP, and Salt Permeation Effects. Both $C_{\mathrm{D}, \mathrm{m}}$ and $C_{\mathrm{F}, \mathrm{m}}$ are local interfacial concentrations on either side of the active layer interface and therefore are not experimentally accessible. To circumvent this, we subtract eq 5 from eq 7 and rearrange to obtain

$$
C_{\mathrm{D}, \mathrm{m}}-C_{\mathrm{F}, \mathrm{m}}=\frac{C_{\mathrm{D}, \mathrm{b}} \exp \left(-\frac{J_{\mathrm{w}}}{k}\right)-C_{\mathrm{F}, \mathrm{b}} \exp \left(\frac{J_{\mathrm{w}} S}{D}\right)}{1+\frac{B}{J_{\mathrm{w}}}\left[\exp \left(\frac{J_{\mathrm{w}} S}{D}\right)-\exp \left(-\frac{J_{\mathrm{w}}}{k}\right)\right]}
$$

Next, we assume that the osmotic pressure is linearly proportional to the salt concentration; i.e., the van't Hoff equation is applicable. Hence, the effective osmotic driving force, $\Delta \pi_{\mathrm{m}}$, is proportional to $\Delta C_{\mathrm{m}}=C_{\mathrm{D}, \mathrm{m}}-C_{\mathrm{F}, \mathrm{m}}$ (eq 8). Substituting $\Delta \pi_{\mathrm{m}}$ into eq 1 yields an expression for the water flux in PRO:

$$
J_{\mathrm{w}}=A\left\{\frac{\pi_{\mathrm{D}, \mathrm{b}} \exp \left(-\frac{J_{\mathrm{w}}}{k}\right)-\pi_{\mathrm{F}, \mathrm{b}} \exp \left(\frac{J_{\mathrm{w}} S}{D}\right)}{1+\frac{B}{J_{\mathrm{w}}}\left[\exp \left(\frac{J_{\mathrm{w}} S}{D}\right)-\exp \left(-\frac{J_{\mathrm{w}}}{k}\right)\right]}-\Delta P\right\}
$$

This equation utilizes experimentally accessible parameters and incorporates the performance-limiting phenomena of ICP and ECP as well as salt leakage across the membrane.

\section{MATERIALS AND METHODS}

Chemicals and Materials. All chemicals used were analytical grade. Polysulfone (PSf) beads $\left(M_{\mathrm{n}} 22000 \mathrm{Da}\right), N, N$-dimethylformamide (DMF, anhydrous, 99.8\%), 1,3-phenylenediamine (MPD, >99\%), and 1,3,5-benzenetricarbonyl trichloride (TMC, 98\%) were used as received (Sigma-Aldrich, St. Louis, MO). TMC was dissolved in Isopar-G, a proprietary nonpolar organic solvent (Univar, Redmond, WA). A thin $(40 \mu \mathrm{m})$, open-structure polyester nonwoven fabric (PET, grade 3249, Ahlstrom, Helsinki, Finland) was used as a backing layer for the PSf supports.

For FO characterization tests, $0.5 \mathrm{M}$ draw solutions were prepared with sodium chloride $(\mathrm{NaCl})$ from J. T. Baker (Phillipsburg, NJ). Solutions for PRO membrane performance tests were prepared by dissolving the appropriate salts in deionized water (DI) (Milli-Q, Millipore, Billerica, MA) and then equilibrating the solutions with the atmosphere for at least $48 \mathrm{~h}$. Compositions and osmotic pressures of the synthetic seawater draw solution as well as the brackish and river water feed solutions are tabulated in Table S1 of the Supporting Information. The ionic strengths of seawater, brackish water, and river water are 696, 19.9, and $1.74 \mathrm{mM}$, respectively.

Polysulfone Porous Support Fabrication. The thin, porous support layer was fabricated by nonsolvent-induced phase separation of PSf on the PET, following the procedure outlined in our previous publications. ${ }^{13,14}$ PSf (9 wt \%) was dissolved in DMF by stirring at room temperature $\left(23^{\circ} \mathrm{C}\right)$ for $8 \mathrm{~h}$ and then stored in a desiccator for at least $15 \mathrm{~h}$ prior to casting. The thin, low-density PET fabric was attached to a clean glass plate using laboratory adhesive tape and then wet with DMF. Any excess solvent that pooled on the surface of the fabric was carefully removed using laboratory wipes. The PSf solution was drawn down the PET fabric using a casting knife (Gardco, Pompano Beach, FL) with an adjustable gate height fixed at $250 \mu \mathrm{m}$ ( $\sim 10$ mils). The whole composite was immediately immersed in a precipitation bath containing 3 wt \% DMF in DI at room temperature to initiate phase separation. ${ }^{9,17}$ The support membrane 
remained in the precipitation bath for $10 \mathrm{~min}$ before being transferred to a DI bath for storage prior to polyamide (PA) formation.

Polyamide Active Layer Fabrication. The PA active layer was formed on top of the hand-cast PSf support layers via interfacial polymerization. ${ }^{13,14}$ The hand-cast support was immersed in a $3.4 \mathrm{wt} \%$ aqueous MPD solution for $120 \mathrm{~s}$, and an air knife was used to remove the excess solution from the membrane surface. Next, the MPD-saturated support membrane was immersed in a $0.15 \mathrm{wt} \% \mathrm{TMC}$ in Isopar-G solution for $60 \mathrm{~s}$ to form the ultrathin PA layer. The composite membrane was then sequentially cured in DI at $95{ }^{\circ} \mathrm{C}$ for $120 \mathrm{~s}$, rinsed with a 200 ppm sodium hypochlorite $(\mathrm{NaOCl})$ aqueous solution for $120 \mathrm{~s}$, soaked in a 1000 ppm sodium bisulfite $\left(\mathrm{NaHSO}_{3}\right)$ aqueous solution for $30 \mathrm{~s}$, and last subjected to a second wet curing step at $95{ }^{\circ} \mathrm{C}$ for $120 \mathrm{~s}$. The fabricated TFC membranes were rinsed thoroughly and stored in DI at $4{ }^{\circ} \mathrm{C}$.

Active Layer Modification. Exposure of the PA active layer to chlorine alters its structure and morphology, resulting in increased water permeability and decreased selectivity (or salt rejection) of the membrane. ${ }^{18,19}$ By careful control of the reaction parameters, water and salt permeabilities of the membrane active layer can be tailored. ${ }^{20}$ Post-treatment was carried out to produce three batches of TFC-PRO membranes with varying active layer transport properties. The first batch of membranes was not subjected to any post-treatment and was designated "LP" for its relatively lower water and salt permeabilities. The second batch was immersed in $1000 \mathrm{ppm} \mathrm{NaOCl}$ aqueous solution adjusted to $\mathrm{pH} 7.0$ for $60 \mathrm{~min}$ and then transferred to a $0.1 \mathrm{M} \mathrm{NaOH}$ aqueous solution for $16 \mathrm{~h}$; this batch was designated as "MP" for its medium water and salt permeabilities. The third batch was treated in $2000 \mathrm{ppm} \mathrm{NaOCl}$ at $\mathrm{pH} 7.0$ for $120 \mathrm{~min}$ before being soaked in $0.1 \mathrm{M} \mathrm{NaOH}$ for 62 $\mathrm{h}$; this batch was designated as "HP" for its high water and salt permeabilities. The post-treated membranes were rinsed thoroughly and stored in DI at $4{ }^{\circ} \mathrm{C}$.

Determination of Membrane Water Permeability and Channel Mass Transfer Coefficient. Intrinsic water permeability of the TFC-PRO membranes was evaluated in a laboratoryscale crossflow RO test unit, as described in our previous work. ${ }^{21}$ Details on the procedure used as well as the calculation of the mass transfer coefficient, $k$, for $\mathrm{NaCl}$ in the spacerfilled channel are given in the Supporting Information. The average, $k$, calculated from eq 9, for the crossflow cell was $38.5 \pm 20.5 \mu \mathrm{m} / \mathrm{s}\left(138.6 \pm 73.9 \mathrm{~L} \mathrm{~m}^{-2} \mathrm{~h}^{-1}\right)$. The relatively large standard deviation is attributed to experimental errors in the measurement of membrane parameters that propagate through the calculation of $k$.

Determination of Membrane Solute Permeability and Structural Parameter. Solute permeability and support layer structural parameter of the membranes were determined in an experimental crossflow FO system described in our previous studies. $^{13,22}$ The custom-built cell has an effective membrane area of $20.02 \mathrm{~cm}^{2}$. Variable speed gear pumps (Cole-Parmer, Vernon Hills, IL) were used to cocurrently circulate the solutions in closed loops at a crossflow velocity of $21.4 \mathrm{~cm} / \mathrm{s}$. No mesh feed spacers were used. A water bath (Neslab, Newington, NH) kept the temperature of both feed and draw solutions constant at $25 \pm$ $0.5{ }^{\circ} \mathrm{C}$. All characterization tests were conducted with the membrane in FO configuration, i.e., the porous support layer facing a $0.5 \mathrm{M} \mathrm{NaCl}$ draw solution and the active layer facing a DI feed solution.
The protocols to measure water and reverse salt flux were adapted from our previous publication. ${ }^{16}$ After equilibrating the FO system, the bypass valves were closed to channel the draw and feed solutions to the membrane cell, and data recording was initiated. Water flux was determined by monitoring the rate of change in weight of the draw solution, and the $\mathrm{NaCl}$ concentration in the feed was measured at 3 min intervals with a calibrated conductivity meter (Oakton Instruments, Vernon Hills, IL). Once water flux had stabilized, concentration data were logged for another $30 \mathrm{~min}$ (i.e., 10 data points).

Solute permeability and support layer structural parameter can be determined from the water flux and reverse salt permeation measurements. Consider a species mass balance on $\mathrm{NaCl}$ in the feed solution

$$
C_{\mathrm{F}, \mathrm{b}}\left(V_{\mathrm{F}_{0}}-J_{\mathrm{w}} A_{\mathrm{m}} t\right)=C_{\mathrm{F}, \mathrm{b}_{0}} V_{\mathrm{F}_{0}}+J_{\mathrm{s}} A_{\mathrm{m}} t
$$

where $C_{\mathrm{F}, \mathrm{b}}$ is the bulk feed solute concentration, $V_{\mathrm{F}_{0}}$ is the initial volume of the feed solution, $J_{\mathrm{w}}$ is the measured water flux, $A_{\mathrm{m}}$ is the membrane area, $t$ is the time elapsed, and $C_{\mathrm{F}, \mathrm{b}_{0}}$ is the initial $\mathrm{NaCl}$ concentration. Reverse salt flux, $J_{s}$, is driven by the difference in salt concentration across the membrane. Since the feed solution is $\mathrm{DI}, J_{\mathrm{s}}$ is the product of draw $(\mathrm{NaCl})$ concentration at the active layer interface and salt permeability coefficient, $B$. The former is approximated by accounting for dilutive internal concentration polarization (ICP) of the bulk draw solution through the factor $\exp \left(-J_{\mathrm{w}} S / D\right)$ :

$$
J_{\mathrm{s}}=B C_{\mathrm{D}, \mathrm{b}} \exp \left(-\frac{J_{\mathrm{w}} S}{D}\right)
$$

where $C_{D, b}$ is the bulk concentration of the draw $(\mathrm{NaCl}), S$ is the structural parameter of the support layer, and $D$ is the diffusion coefficient of the draw solute. The structural parameter is obtained from ${ }^{23}$

$$
S=\left(\frac{D}{J_{\mathrm{w}}}\right) \ln \left(\frac{B+A \pi_{\mathrm{D}, \mathrm{b}}}{B+J_{\mathrm{w}}}\right)
$$

where $\pi_{\mathrm{D}, \mathrm{b}}$ is the osmotic pressure of the bulk draw solution. Substitution of eqs 11 and 12 into eq 10 yields

$$
C_{\mathrm{F}, \mathrm{b}}=\frac{C_{\mathrm{F}, \mathrm{b}_{0}} V_{\mathrm{F}_{0}}+B C_{\mathrm{D}, \mathrm{b}}\left(\frac{B+J_{\mathrm{w}}}{B+A \pi_{\mathrm{D}, \mathrm{b}}}\right) A_{\mathrm{m}} t}{\left(V_{\mathrm{F}_{0}}-J_{\mathrm{w}} A_{\mathrm{m}} t\right)}
$$

The membrane water permeability, $A$, is determined from the RO test, and $C_{\mathrm{F}, \mathrm{b}}, V_{\mathrm{F}_{0}}, C_{\mathrm{D}, \mathrm{b}}, \pi_{\mathrm{D}, \mathrm{b}}$, and $A_{\mathrm{m}}$ are known experimental parameters. The solute permeability coefficient, $B$, and membrane structural parameter, $S$, can be calculated using eqs 12 and 13 by fitting feed concentration data as a function of time together with the measured $J_{\mathrm{w}}$.

Determination of Membrane Performance in PRO Mode. One fabricated membrane from each batch (LP\#1, MP\#1, and HP\#1) was tested in the FO system with the synthetic seawater draw solution (Table S1, Supporting Information) for PRO water flux performance at zero applied hydraulic pressure. Experimental runs were conducted with river and brackish water feed solutions (Table S1, Supporting Information) to simulate scenarios with different input streams. The membranes were oriented in PRO configuration (i.e., with the active layer facing 
the draw solution). Mesh spacers were employed in the draw channel to improve mixing, and both draw and feed streamflow rates were maintained at $1.0 \mathrm{~L} / \mathrm{min}(21.4 \mathrm{~cm} / \mathrm{s}$ crossflow velocity in feed channel) in cocurrent crossflow. The setup was maintained at a constant temperature of $25 \pm 0.5^{\circ} \mathrm{C}$. Water flux was measured by monitoring the rate of change in weight of the draw solution, averaged over a $30 \mathrm{~min}$ period after it had stabilized.

Prediction of PRO Water Flux and Power Density. The water flux in PRO accounting for dilutive external concentration polarization (ECP) in the draw stream, concentrative ICP, and build up of leaked draw salts in the porous support layer is described by eq 9 , derived in the Theory section. The power density, $W$, is defined as the power generated per unit membrane area:

$$
W=J_{\mathrm{w}} \Delta P
$$

With inputs of known membrane characteristic parameters $A$, $B$, and $S$; solution properties $\pi_{\mathrm{D}, \mathrm{b}}, \pi_{\mathrm{F}, \mathrm{b}}$, and $D$; and mass transfer coefficient $k$, eq 9 can be solved numerically to obtain the theoretical PRO water flux over a range of applied pressures. The corresponding power densities can then be determined with eq 14. For predicting performance of the fabricated TFC-PRO membranes with the synthetic seawater draw solution, the solute permeability coefficient, diffusion coefficient, and mass transfer coefficient for $\mathrm{NaCl}$ were used as approximations for coefficients of the multicomponent system. Osmotic pressure of synthetic seawater was calculated by a software package from OLI Systems, Inc. (Morris Plains, NJ), while osmotic pressures of river and brackish water were determined by the van't Hoff equation.

\section{RESULTS AND DISCUSSION}

Validation of the PRO Water Flux Model. To validate the derived water flux model, a commercial cellulose triacetate (CTA) FO membrane (Hydration Technology Inc., Albany, OR) was tested in a PRO system under a range of applied hydraulic pressures. Details on the PRO system and experiment are given in the Supporting Information. Characteristic parameters $A, B$, and $S$ of the CTA membrane based on our recent study ${ }^{13}$ were used in conjunction with eqs 9 and 14 to predict the water flux, $J_{\mathrm{w}}$, and power density, $W$, as a function of applied hydraulic pressure, $\triangle P$. The model predictions for $J_{\mathrm{w}}$ and $W$ and the measured $J_{\mathrm{w}}$ data at $\Delta P$ between 0 and 10.3 bar are presented in Figure $S 3$ of the Supporting Information. The good agreement between actual and predicted water flux values validates the derived model. Therefore, eqs 9 and 14 can be utilized to adequately project the peak power densities achievable by our fabricated TFC-PRO membranes by extrapolating from the experimental PRO water flux at no applied hydraulic pressure.

Membrane Characteristics. Representative scanning electron microscope (SEM) micrographs of the hand-cast TFCPRO membrane are presented in Figure 2. Figure 2A shows a cross-sectional micrograph of a TFC-PRO membrane, demonstrating that large fingerlike macrovoids $(\sim 10 \mu \mathrm{m}$ width) span almost the entire support layer thickness. A close inspection of Figure $2 \mathrm{~A}$ reveals that a less porous spongelike morphology is present in the top skin portion of the PSf support (Figure 2C). Previous studies demonstrated that this specific structure is capable of minimizing the detrimental effects of ICP while allowing the formation of a polyamide layer that possesses high water permeability and salt rejection properties. ${ }^{13,14}$

A thin, spongelike skin layer forming on top of a layer containing macrovoids indicates that the two layers undergo
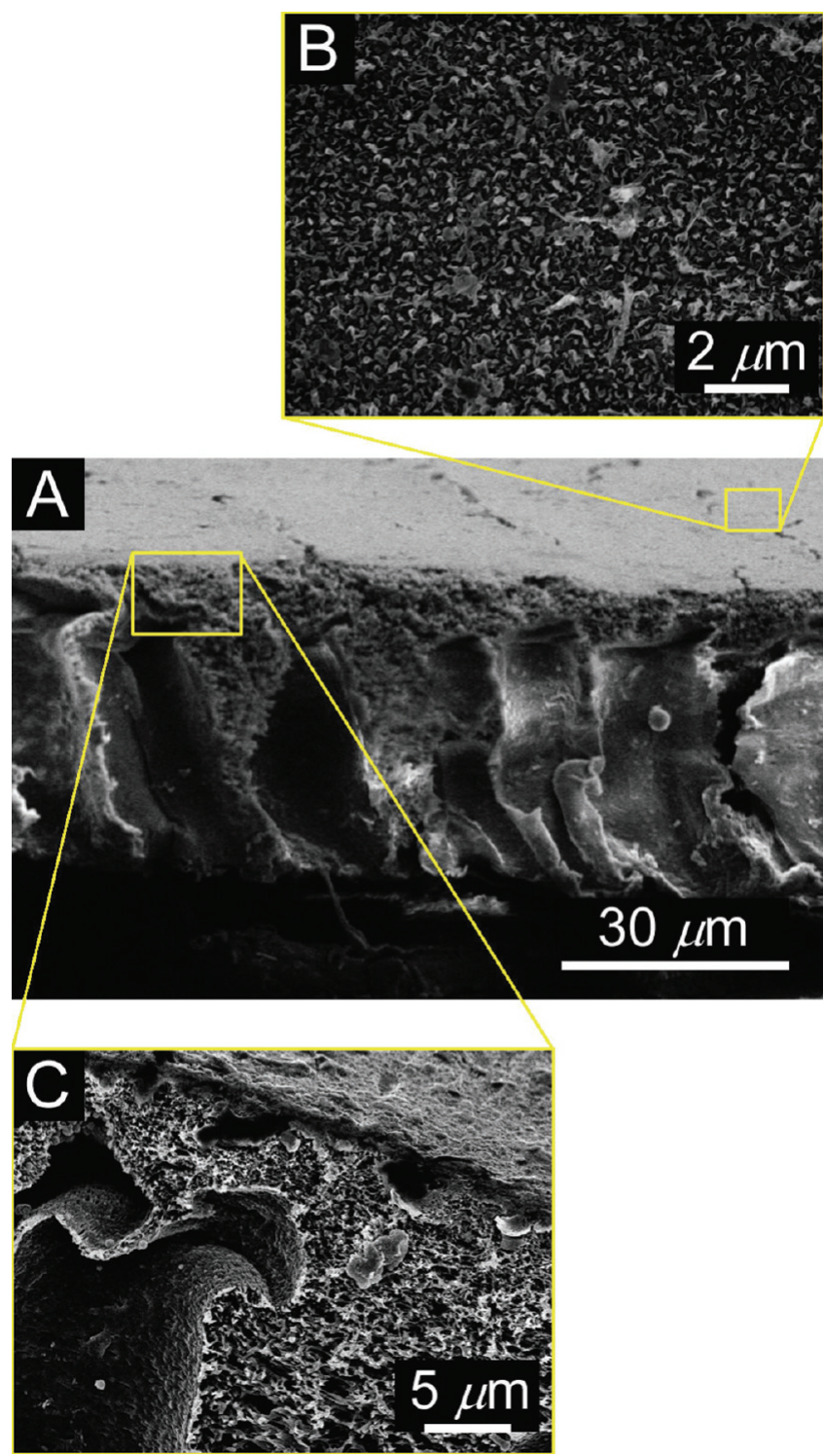

Figure 2. SEM micrographs of a TFC-PRO membrane with PET fabric layer removed: (A) cross section with a fingerlike macrovoid structure extending across the entire PSf support layer, (B) magnified view of the polyamide active layer surface, and (C) magnified view of the skin layer at the top of the PSf porous support with dense, spongelike morphology. The magnified views are representative images and do not correspond to the actual locations on the center micrograph. Details on SEM characterization are given in the Supporting Information.

different formation pathways during the phase separation process. $^{14,24}$ Because the solvent of the casting solution is DMF, which has a relatively low heat of mixing with the nonsolvent (water), ${ }^{25}$ when the polymer solution is plunged into the nonsolvent bath, the ratio of solvent outflux to water influx is high. This results in the top portion of the polymer film beginning to gel before the initiation of phase separation, thereby producing a dense spongelike skin layer near the top of the support layer (Figure 2C). ${ }^{17,26}$ As the phase separation process progresses, the relatively low viscosity of the $9 \mathrm{wt} \%$ polymer solution allows for the rapid influx of nonsolvent (i.e., rapid demixing conditions), resulting in the phase separation front moving faster than the gelation front. ${ }^{27}$ The rapid demixing 
Table 1. Summary of Membrane Characteristic Parameters and Modeled Peak Power Densities for All TFC-PRO Membranes Fabricated

\begin{tabular}{|c|c|c|c|c|c|}
\hline \multirow[b]{2}{*}{ membrane } & \multirow[b]{2}{*}{$\begin{array}{l}\text { intrinsic water permeability, } \\
\qquad A\left(\mathrm{~L} \mathrm{~m}^{-2} \mathrm{~h}^{-1} \mathrm{bar}^{-1}\right)\end{array}$} & \multirow[b]{2}{*}{$\begin{array}{c}\text { solute permeability } \\
\text { coefficient, }{ }^{b} B\left(\mathrm{~L} \mathrm{~m}^{-2} \mathrm{~h}^{-1}\right)\end{array}$} & \multirow[b]{2}{*}{ structural parameter, $^{b} S(\mu \mathrm{m})$} & \multicolumn{2}{|c|}{ peak power density, ${ }^{c} W_{\text {peak }}$} \\
\hline & & & & river water $\left(\mathrm{W} / \mathrm{m}^{2}\right)$ & brackish water $\left(\mathrm{W} / \mathrm{m}^{2}\right)$ \\
\hline $\mathrm{LP} \# 1$ & 1.74 & 0.16 & 307 & 6.09 & 5.29 \\
\hline $\mathrm{LP} \# 2$ & 1.42 & 0.08 & 355 & 5.24 & 4.56 \\
\hline $\mathrm{LP} \# 3$ & 1.71 & 0.09 & 384 & 6.03 & 5.09 \\
\hline avg & 1.63 & 0.11 & 349 & 5.79 & 4.98 \\
\hline SD & 0.18 & 0.04 & 39 & 0.47 & 0.38 \\
\hline $\mathrm{MP \# 1}$ & 5.81 & 0.88 & 370 & 10.0 & 7.69 \\
\hline $\mathrm{MP} \# 2$ & 4.08 & 0.77 & 332 & 9.21 & 7.38 \\
\hline $\mathrm{MP} \# 3$ & 3.16 & 0.61 & 316 & 8.37 & 6.90 \\
\hline avg & 4.35 & 0.76 & 340 & 9.21 & 7.33 \\
\hline SD & 1.34 & 0.14 & 28 & 0.84 & 0.40 \\
\hline HР\# 1 & 7.55 & 5.45 & 327 & 6.08 & 5.16 \\
\hline $\mathrm{HP} \# 2$ & 7.35 & 4.12 & 336 & 6.82 & 5.71 \\
\hline HР\#3 & 7.76 & 3.86 & 416 & 5.78 & 4.80 \\
\hline avg & 7.55 & 4.48 & 360 & 6.23 & 5.22 \\
\hline SD & 0.20 & 0.85 & 49 & 0.54 & 0.46 \\
\hline
\end{tabular}

${ }^{a}$ Determined by permeate flux measurement in RO tests at $17.2 \mathrm{bar}(250 \mathrm{psi})$ with DI feed solution at $25^{\circ} \mathrm{C} .{ }^{b}$ Determined by water flux and reverse salt flux measurements in $\mathrm{FO}$ tests with $0.5 \mathrm{M} \mathrm{NaCl}$ draw solution and $\mathrm{DI}$ feed solution at $25^{\circ} \mathrm{C} .{ }^{\circ}$ Calculated using eqs 9 and 14 with seawater draw solution and river water or brackish water feed solutions at $25^{\circ} \mathrm{C}$.

conditions, coupled with the higher concentration of polymerpoor regions, ${ }^{28}$ promote the formation of macrovoids that span most of the support layer thickness (Figure 2A). ${ }^{29}$ Additionally, prewetting the PET fabric with DMF facilitated the formation of macrovoids that remain open at the PSf-PET interface, which is critical to minimizing ICP. ${ }^{14}$

The values of the structural parameter $S(349 \pm 35 \mu \mathrm{m}$, averaged over all nine membranes), calculated from FO experiments (Table 1) verify the high porosity and low tortuosity of the hand-cast support layer. The three different membrane formulations-LP, MP, and HP_had comparable $S$ values, which is expected because the same fabrication process was followed for all the support layers. Furthermore, these values are consistent with previous experiments ${ }^{14}$ and confirm the ability of this particular support structure to minimize ICP.

Figure $2 \mathrm{~B}$ presents an SEM micrograph of the TFC-PRO membrane active layer. The image shows a visually uniform ridge-and-valley morphology, which is typical of polyamide thin films formed by interfacial polymerization. ${ }^{30}$ The resulting TFCPRO membranes have an average water permeability coefficient, $A$, of $1.63 \pm 0.18 \mathrm{~L} \mathrm{~m}^{-2} \mathrm{~h}^{-1} \mathrm{bar}^{-1}$ and an average salt $(\mathrm{NaCl})$ permeability coefficient, $B$, of $0.11 \pm 0.04 \mathrm{~L} \mathrm{~m}^{-2} \mathrm{~h}^{-1}$. We designate these membranes LP for "low permeability" in Table 1. These values of the $A$ and $B$ permeability coefficients are consistent with those for previous hand-cast thin-film composite polyamide membranes. ${ }^{14,31,32}$

We modified the transport properties of some membranes through chlorine and alkaline post-treatments of the polyamide thin films. The reactant concentrations, $\mathrm{pH}$, and exposure times were controlled during the active layer modification to enhance the water flux at the expense of some salt retention capabilities. ${ }^{20}$ Although the exact reason for these changes is not well understood, several mechanisms have been proposed to explain the phenomenon, including Orton rearrangement, ${ }^{33}$ direct aromatic ring chlorination, ${ }^{34}$ and change in hydrogen-bonding behavior.

The membranes were subjected to one of two different posttreatments. The milder process resulted in an approximately 3-fold increase in $A$ to $4.35 \pm 1.34 \mathrm{~L} \mathrm{~m}^{-2} \mathrm{~h}^{-1} \mathrm{bar}^{-1}$ and an increased $B$ of $0.76 \pm 0.14 \mathrm{~L} \mathrm{~m}^{-2} \mathrm{~h}^{-1}$. These samples are designated MP for "medium permeability" (Table 1). The stronger treatment produced TFC membranes with significantly higher $A$ and $B$ values of $7.55 \pm 0.20 \mathrm{~L} \mathrm{~m}^{-2} \mathrm{~h}^{-1} \mathrm{bar}^{-1}$ and $4.48 \pm$ $0.85 \mathrm{~L} \mathrm{~m}^{-2} \mathrm{~h}^{-1}$, respectively (designated HP for "high permeability" in Table 1). SEM micrographs of the different active layers (Figure S2 of Supporting Information) indicate a similar ridge-and-valley morphology, with little or no distinguishable difference from the unmodified membrane.

Water Flux and Projected Power Density of Hand-Cast TFC-PRO Membranes. Experimentally measured water fluxes for our fabricated membranes, $L P \# 1, M P \# 1$, and $H P \# 1$, are presented in Figure 3. Measurements were made with no applied hydraulic pressure using a synthetic seawater draw solution and both river water and brackish water feed solutions (indicated by open square and circles, respectively). The characteristic membrane parameters, $A, B$, and $S$, of the different membranes are displayed above the water flux plots as bar graphs. These characteristic properties are used in conjunction with eqs 9 and 14 to extrapolate the water flux and power density as a function of applied hydraulic pressure. The solid and dashed lines show the calculated power densities for river water and brackish water feed solutions, respectively. A horizontal dashed line, corresponding to a power density $W$ of $5 \mathrm{~W} / \mathrm{m}^{2}$, is included as a visual guide in the plots of power density. There is generally good agreement 

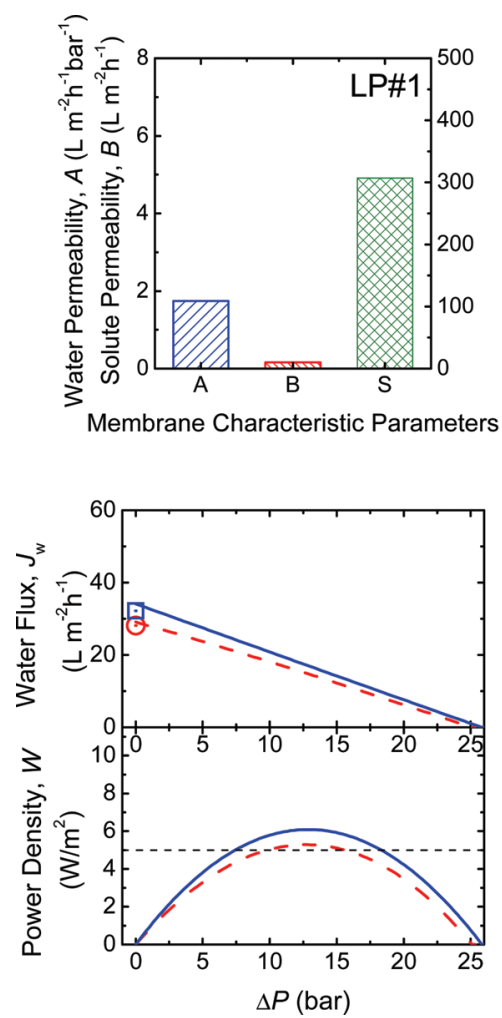

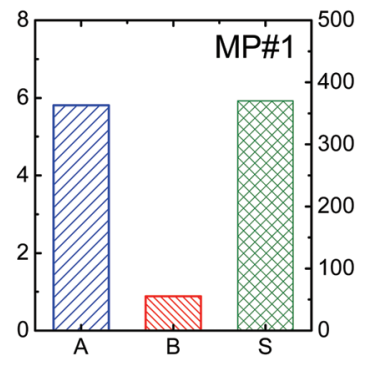

Membrane Characteristic Parameters

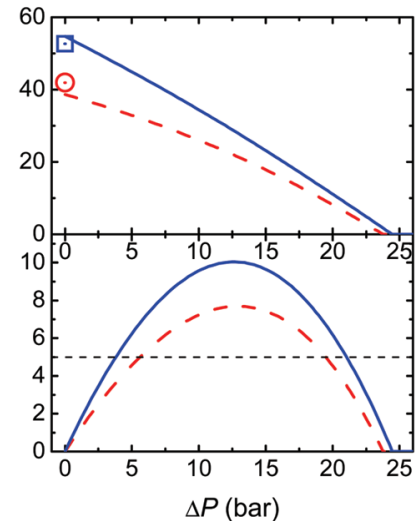

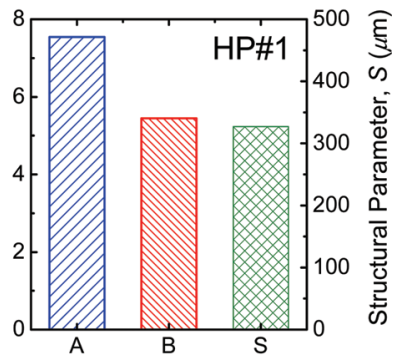

Membrane Characteristic Parameters

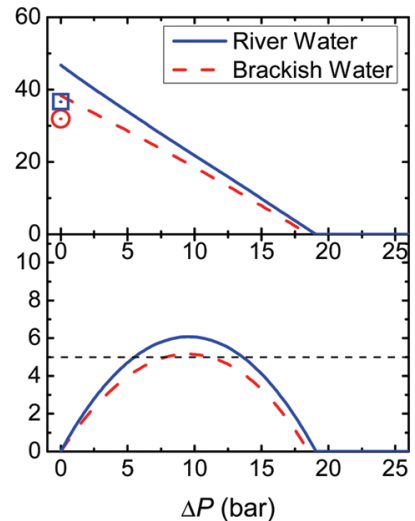

Figure 3. Plots of modeled water flux, $J_{\mathrm{w}}$, and power density, $W$, (bottom) as a function of applied hydraulic pressure, $\triangle P$, for TFC-PRO LP\# 1 (left), MP\#1 (center), and HP\#1 (right) membranes and their respective characteristic parameters (top): intrinsic water permeability, $A$; solute permeability coefficient, $B$; and support layer structural parameter, $S$. Osmotic pressure of synthetic seawater is 26.14 bar, as determined by OLI Stream Analyzer software, and osmotic pressures of synthetic river water and 1,000 ppm TDS brackish water are 0.045 and 0.789 bar, respectively, as calculated using the van't Hoff equation. Symbols (open squares and circles) represent measured experimental water fluxes of the membrane with synthetic river water and brackish water as feed solutions, respectively. All experiments and calculations are done for draw and feed solutions at $25^{\circ} \mathrm{C}$.

between our experimental data obtained at no applied hydraulic pressure and the theoretical predictions. The water flux $J_{\mathrm{w}}$ is slightly overpredicted for HP\#1 due to the variation of the mass transfer coefficient $k$ as previously discussed.

The power density of the membranes investigated increases with increasing $\Delta P$, until it reaches a maximum value of $W_{\text {peak }}$ when the applied hydraulic pressure is approximately half of the osmotic pressure difference across the membrane, i.e., $\Delta P \approx\left(\pi_{\mathrm{D}}\right.$ $\left.-\pi_{\mathrm{F}}\right) / 2$. The predicted peak power densities of the nine fabricated TFC-PRO membranes are summarized in Table 1. Membranes with different active layer formulation, i.e., LP, MP, and HP, exhibit different $W_{\text {peak. }}$. For example, with a river water feed solution and a seawater draw solution, the values of $W_{\text {peak }}$ are $6.09,10.0$, and $6.08 \mathrm{~W} / \mathrm{m}^{2}$ for $\mathrm{LP} \# 1, \mathrm{MP} \# 1$, and $\mathrm{HP} \# 1$, respectively. For a brackish water feed solution, the $W_{\text {peak }}$ values for LP\#1, MP\#1, and HP\# 1 are slightly less, at 5.29, 7.69, and 5.16 $\mathrm{W} / \mathrm{m}^{2}$, respectively, due to the higher salt concentration of the feed solution. In all cases, the $W_{\text {peak }}$ values exceed $5 \mathrm{~W} / \mathrm{m}^{2}$ and are the highest PRO peak power densities reported to date. ${ }^{2}$ The outstanding performance of the TFC-PRO membranes is attributed to the combination of a customized support layer, which minimizes ICP, and an active layer that possesses high water permeability and moderately low salt permeability.

PRO Power Density Depends on Support and Active Layer Membrane Properties. The progress in power generation by PRO has been hindered by the absence of a suitable membrane. ${ }^{2,6,35}$ Commercial membranes employed in previous studies lacked the right combination of transport properties, thereby limiting the $W_{\text {peak }}$ to $<3.5 \mathrm{~W} / \mathrm{m}^{2}$ when using a draw solution of approximately seawater concentration. ${ }^{2}$ In this section, we discuss the role of the support layer structural parameter as well as active layer transport properties-salt and water permeabilitiesin PRO water flux and power density performance.

a. Support Layer Structural Parameter. As water from the feed solution (river or brackish water) permeates across the active layer into the draw solution (seawater), the semipermeable layer retains salts from the feed solution, causing their local concentration within the support layer to increase. The buildup of salt concentration adversely affects PRO performance by increasing the local osmotic pressure of the feed solution, which decreases the effective osmotic driving force, thereby diminishing the water flux. ${ }^{6,36}$ Diffusion works to restore the concentration to that of the bulk feed solution but is limited by the porous support of the membrane, which acts as an unstirred boundary layer and determines the extent of internal concentration polarization. The detrimental effect of ICP can be seen by examining the PRO water flux equation, eq 9, where the feed solution osmotic pressure $\pi_{\mathrm{F}, \mathrm{b}}$ is magnified by a factor of $\exp \left(J_{\mathrm{w}} S / D\right)$.

The support layer structural parameter $S$ is determined solely by the microstructure of the support membrane and is defined as $S=t_{\mathrm{s}} \tau / \varepsilon$, where $t_{\mathrm{s}}$ is the support thickness, $\tau$ is the tortuosity, and $\varepsilon$ is the porosity. $S$ has units of length and can be regarded as the characteristic distance a solute particle must diffuse from the active layer-porous support interface of the membrane to reach 
the bulk feed solution. When this distance is shorter, diffusion is more effective at restoring the concentration at the interface to that in the bulk feed solution. By thoughtful control of the support layer casting conditions, a membrane with a thin, porous, and nontortuous support layer was fabricated in this study, which allows for a low $S(349 \pm 35 \mu \mathrm{m})$ to be achieved. The low value of $S$ minimizes the effective thickness of the ICP boundary layer, thereby allowing for higher water flux and power density performance.

b. Active Layer Salt Permeability. ICP is exacerbated by the reverse flux of draw solute, ${ }^{16}$ whereby the solute permeates from the more concentrated draw solution (seawater) into the feed solution (river or brackish water). The leaked solute accumulates in the porous support and further increases the interfacial osmotic pressure, producing an additional reduction of the osmotic driving force. The negative effects of this coupling between reverse salt permeation and ICP is reflected in the denominator of eq 9, where the osmotic pressure difference across the membrane is reduced by a factor of $1+B / J_{\mathrm{w}}\left[\exp \left(J_{\mathrm{w}} S / D\right)-\right.$ $\left.\exp \left(-J_{\mathrm{w}} / k\right)\right]$. To mitigate this adverse effect, the membrane salt permeability, $B$, needs to be minimized. Although the PRO requirements for salt rejection are relaxed compared to $\mathrm{FO}$ systems, sufficient retention is necessary to keep an adequate osmotic driving force.

Both $B$ and $S$ need to be low to reduce the negative effect of reverse salt flux. A membrane with a large structural parameter will have its performance severely limited by the effects of the reverse solute flux, even if it has a relatively low solute permeability. ${ }^{6}$ For example, commercial RO membranes have thick and dense support layers with large $S$ on the order of 10000 $\mu \mathrm{m}^{13}$ and hence suffer from severe ICP effects. ${ }^{13,22}$ The effect of reverse salt permeation coupled with severe ICP is evident in PRO when the feed solution used is DI. Despite the absence of solute from the feed stream, i.e., $\pi_{\mathrm{F}, \mathrm{b}}=0$, and a relatively low salt permeability $B$, any small amount of salt leaked over from the draw solution builds up within the porous support due to severely hindered diffusion. The detrimental effect of this increased leaked salt concentration on water flux is readily seen by examining eq 9. Due to the large $S$, the exponential ICP term, $\exp \left(J_{w} S / D\right)$, overwhelms the relatively small $B$ and the ECP term, $\exp \left(-J_{\mathrm{w}} / k\right)$, which ranges between 0 and 1 . The large ICP term dominates the denominator expression, meaning that ICP markedly reduces the osmotic driving force across the membrane, which leads to a severely diminished water flux. Along with the low $S$ parameter of the support layer, the TFC-PRO membranes fabricated in our study also have low values of $B$ to adequately suppress reverse salt flux.

c. Active Layer Water Permeability. The driving force for water flux is the difference between the effective osmotic pressure, which accounts for the effects of concentration polarization, and the applied hydraulic pressure. Water flux in PRO is equal to the driving force multiplied by the membrane intrinsic water permeability, $A$, as stated in eq 9. The commercial CTA FO membrane investigated in a previous PRO study yielded a modest $W_{\text {peak }}$ of $\sim 2.7 \mathrm{~W} / \mathrm{m}^{2}$ despite having both a relatively low $S$ of $\sim 678 \mu \mathrm{m}$ and a low $B$ of $0.40 \mathrm{~L} \mathrm{~m}^{-2} \mathrm{~h}^{-1}$. Because asymmetric cellulose triacetate membranes have inherently lower $A$ values $\left(0.67 \mathrm{~L} \mathrm{~m}^{-2} \mathrm{~h}^{-1} \mathrm{bar}^{-17}\right.$ ) when compared to TFC membranes (e.g., $A$ values summarized in Table 1 ), their performance is limited. ${ }^{13,22}$ During the fabrication of our TFCPRO membranes, the support and active layers were formed in separate steps, allowing the properties of the two layers to be tailored almost independently of each other. By careful fabrication and modification of the membrane active layer, our TFC-PRO membranes were able to achieve higher water permeabilities with a moderate decline in salt retention capabilities. This active layer combined with the thin, porous support layer results in a higher water flux and power density.

Balancing Membrane Permeability-Selectivity to Maximize PRO Performance. As the membranes become more permeable to water, i.e., $\mathrm{LP} \rightarrow \mathrm{MP} \rightarrow \mathrm{HP}$, a corresponding increase in $J_{\mathrm{w}}$ and $W_{\text {peak }}$ was not always observed. The three membrane formulations have comparable values of $S$ and hence experience a similar degree of ICP. Despite HP\#1 having the highest $A$, its achievable $W_{\text {peak }}$ was significantly lower than the less permeable MP\#1. This observation can be attributed to the substantially higher solute permeability of $\mathrm{HP} \# 1$, which leads to more reverse salt permeation. The higher $A$ of HP\#1 ( 30\% greater than that of MP\#1) was accompanied by a disproportionate increase in $B$ (over 6 times greater than that of MP\#1). Consequently, the adverse effect of reverse salt permeation coupled with ICP is severely amplified, overwhelming the benefit of higher water permeability. Therefore, the resulting water flux and power density are markedly reduced.

In order to maximize $\mathrm{PRO}$ performance, the membrane active layer should have a high $A$ and a low $B$. However, progress toward this ideal situation is limited by the permeability-selectivity trade-off that governs current separation membranes, ${ }^{37,38}$ including polyamide TFC membranes, ${ }^{15,28,30}$ where an increase in water permeability is accompanied by an increase in salt permeation. Increasing the value of $A$ up to a certain point benefits the PRO process because it allows for a higher water flux, after which the corresponding increase in $B$ will result in the PRO productivity being hindered by the reverse permeation of draw solute. Therefore, to maximize the peak power density that can be achieved by a membrane in PRO, the active layer needs to be designed by balancing the trade-off between permeability and selectivity.

Balancing the trade-off between permeability and selectivity of PRO membranes will depend on the specific support layer structural parameter. The low $S$ value of our fabricated membranes is essential to take advantage of more permeable but less selective active layers. The membranes are able to tolerate greater increases in $B$ than membranes with a larger $S$ value (e.g., commercial RO membranes) because the low $S$ enables fast diffusion to keep the solution within the support sufficiently mixed, thereby mitigating the detrimental effect of reverse salt permeation. Hence, we are able to exploit the higher $A$ and achieve a significantly higher $W_{\text {peak }}$.

Implications for Osmotic Power Generation. The membranes developed in this work demonstrate the potential to produce high power densities in PRO with natural salinity gradients in excess of the goal of $5 \mathrm{~W} / \mathrm{m}^{2}$ necessary to produce osmotic power cost-effectively. ${ }^{12}$ Important considerations for the design of future high-performance PRO membranes are highlighted in this study. The experimental and simulated results illustrate that the PRO performance of a membrane can be maximized when the active layer transport properties are tailored to the support layer. For a particular support layer structural parameter $S$, the active layer permeabilities can be optimized to achieve the highest $W_{\text {peak }}$ by balancing the benefit of a higher water permeability with the drawback of greater reverse salt leakage. A thin and porous support layer is crucial to exploiting a highly permeable but less selective active layer. By reducing ICP, 
a lower $S$ value increases the membrane tolerance for the reverse permeation of salt, which enables the membrane to attain a greater $W_{\text {peak }}$.

River water is a precious resource, due to its lower concentration of dissolved solids, and hence brackish water may be a more feasible feed stream for a PRO plant to produce energy. The extrapolated performance for our highest performing membrane suggests that brackish water could be utilized as feed solution to produce a peak power density of $7.69 \mathrm{~W} / \mathrm{m}^{2}$ at an applied pressure near 13 bar. Alternatively, the same system could be operated at a lower applied hydraulic pressure of 5.6 bar and still meet the proposed goal of $5 \mathrm{~W} / \mathrm{m}^{2}$. This ability to operate at a reduced hydraulic pressure allows for greater flexibility when balancing the need to produce a thin porous support layer with one that can reliably withstand the mechanical stresses generated during operation.

\section{ACKNOWLEDGMENT}

This publication is based on work supported in part by Award No. KUS-C1-018-02, made by King Abdullah University of Science and Technology (KAUST); the WaterCAMPWS, a Science and Technology Center of Advanced Materials for the Purification of Water with Systems under the National Science Foundation Grant CTS-0120978; and Oasys Water Inc. We also acknowledge the Graduate Fellowship (to Ngai Yin Yip) made by the Environment and Water Industrial Development Council of Singapore and the NWRI-AMTA Fellowship for membrane technology (to Alberto Tiraferri). Lastly, we thank Baoxia Mi and her research group at George Washington University for useful guidance on protocols for interfacial polymerization.

\section{ASSOCIATED CONTENT}

S Supporting Information. Details on the SEM characterization and determination of intrinsic water permeability coefficient of hand-cast TFC-PRO membranes; details on the determination of membrane channel mass transfer coefficient in PRO; validation of the PRO water flux model with experimental data; schematic diagram of the laboratory-scale PRO system (Figure S1); additional SEM micrographs of the polyamide active layer surface of the LP, MP, and HP membranes (Figure S2); plot of the measured water flux and calculated power density as a function of the applied hydraulic pressure fitted to model predictions for the commercial CTA FO membrane (Figure S3); and summary of the ionic composition and osmotic pressure of the synthetic seawater, brackish water, and river water solutions (Table S1). This material is available free of charge via the Internet at http://pubs.acs.org.

\section{AUTHOR INFORMATION}

\section{Corresponding Author}

*E-mail: menachem.elimelech@yale.edu; phone: (203) 4322789.

\section{REFERENCES}

(1) Evans, A.; Strezov, V.; Evans, T. J. Assessment of sustainability indicators for renewable energy technologies. Renewable Sustainable Energy Rev. 2009, 13 (5), 1082-1088.
(2) Achilli, A.; Childress, A. E. Pressure retarded osmosis: From the vision of Sidney Loeb to the first prototype installation-Review. Desalination 2010, 261 (3), 205-211.

(3) Thorsen, T.; Holt, T. The potential for power production from salinity gradients by pressure retarded osmosis. J. Membr. Sci. 2009, 335 (1-2), 103-110

(4) Loeb, S. Production of energy from concentrated brines by pressure-retarded osmosis. 1. Preliminary technical and economic correlations. J. Membr. Sci. 1976, 1 (1), 49-63.

(5) McGinnis, R. L.; McCutcheon, J. R.; Elimelech, M. A novel ammonia-carbon dioxide osmotic heat engine for power generation. J. Membr. Sci. 2007, 305 (1-2), 13-19.

(6) Lee, K. L.; Baker, R. W.; Lonsdale, H. K. Membranes for powergeneration by pressure-retarded osmosis. J. Membr. Sci. 1981, 8 (2), 141-171.

(7) Achilli, A.; Cath, T. Y.; Childress, A. E. Power generation with pressure retarded osmosis: An experimental and theoretical investigation. J. Membr. Sci. 2009, 343 (1-2), 42-52.

(8) Xu, Y.; Peng, X. Y.; Tang, C. Y. Y.; Fu, Q. S. A.; Nie, S. Z. Effect of draw solution concentration and operating conditions on forward osmosis and pressure retarded osmosis performance in a spiral wound module. J. Membr. Sci. 2010, 348 (1-2), 298-309.

(9) Baker, R. W. Membrane Technology and Applications, 2nd ed.; J. Wiley: New York, 2004; p x, 538 pp.

(10) Vos, K. D.; Burris, F. O.; Riley, R. L. Kinetic study of hydrolysis of cellulose acetate in $\mathrm{pH}$ range of 2-10. J. Appl. Polym. Sci. 1966, 10 (5), $825-832$.

(11) Brekke, G. The Statkraft prototype plant. http://osmosis-summit. event123.no/programsummit2010.cfm.

(12) Skilhagen, S. E. Osmotic power-A new, renewable energy source. Desalination Water Treat. 2010, 15 (1-3), 271-278.

(13) Yip, N. Y.; Tiraferri, A.; Phillip, W. A.; Schiffman, J. D.; Elimelech, M. High performance thin-film composite forward osmosis membrane. Environ. Sci. Technol. 2010, 44 (10), 3812-3818.

(14) Tiraferri, A.; Yip, N. Y.; Phillip, W. A.; Schiffman, J. D.; Elimelech, M. Relating performance of thin-film composite forward osmosis membranes to support layer formation and structure. J. Membr. Sci. 2011, 367 (1-2), 340-352.

(15) Geise, G. M.; Park, H. B.; Sagle, A. C.; Freeman, B. D.; McGrath, B. E. Water Permeability and Water/Salt Selectivity Tradeoff in Polymers for Desalination. J. Membr. Sci. 2011, 369, 130-138.

(16) Phillip, W. A.; Yong, J. S.; Elimelech, M. Reverse draw solute permeation in forward osmosis: Modeling and experiments. Environ. Sci. Technol. 2010, 44 (13), 5170-5176.

(17) van de Witte, P.; Dijkstra, P. J.; van den Berg, J. W. A.; Feijen, J. Phase separation processes in polymer solutions in relation to membrane formation. J. Membr. Sci. 1996, 117 (1-2), 1-31.

(18) Glater, J.; Zachariah, M. R.; Mccray, S. B.; Mccutchan, J. W. Reverse-osmosis membrane sensitivity to ozone and halogen disinfectants. Desalination 1983, 48 (1), 1-16.

(19) Kwon, Y. N.; Leckie, J. O. Hypochlorite degradation of crosslinked polyamide membranes-II. Changes in hydrogen bonding behavior and performance. J. Membr. Sci. 2006, 282 (1-2), 456-464.

(20) Jons, S. D.; Stutts, K. J.; Ferritto, M. S. Mickols, W. E. Treatment of composite polyamide membrane to improve performance. Patent 5876602, 1999.

(21) Ang, W. S.; Elimelech, M. Protein (BSA) fouling of reverse osmosis membranes: Implications for wastewater reclamation. J. Membr. Sci. 2007, 296 (1-2), 83-92.

(22) McCutcheon, J. R.; McGinnis, R. L.; Elimelech, M. A novel ammonia-carbon dioxide forward (direct) osmosis desalination process. Desalination 2005, 174 (1), 1-11.

(23) Cath, T. Y.; Childress, A. E.; Elimelech, M. Forward osmosis: Principles, applications, and recent developments. J. Membr. Sci. 2006, 281 (1-2), 70-87.

(24) Wijmans, J. G.; Kant, J.; Mulder, M. H. V.; Smolders, C. A. Phase-separation phenomena in solutions of polysulfone in mixtures of a 
solvent and a nonsolvent-Relationship with membrane formation. Polymer 1985, 26 (10), 1539-1545.

(25) Yanagishita, H.; Nakane, T.; Yoshitome, H. Selection criteria for solvent and gelation medium in the phase inversion process. J. Membr. Sci. 1994, 89 (3), 215-221.

(26) Mulder, M. H. V.; Hendrikman, J. O.; Wijmans, J. G.; Smolders, C. A. A Rationale for the preparation of asymmetric pervaporation membranes. J. Appl. Polym. Sci. 1985, 30 (7), 2805-2820.

(27) McKelvey, S. A.; Koros, W.J. Phase separation, vitrification, and the manifestation of macrovoids in polymeric asymmetric membranes. J. Membr. Sci. 1996, 112 (1), 29-39.

(28) Mulder, M. Basic Principles of Membrane Technology, 2nd ed.; Kluwer Academic: Dordrecht, 1996; p 564.

(29) Smolders, C. A.; Reuvers, A. J.; Boom, R. M.; Wienk, I. M. Microstructures in phase-inversion membranes. 1. Formation of macrovoids. J. Membr. Sci. 1992, 73 (2-3), 259-275.

(30) Petersen, R. J. Composite reverse-osmosis and nanofiltration membranes. J. Membr. Sci. 1993, 83 (1), 81-150.

(31) Ghosh, A. K.; Hoek, E. M. V. Impacts of support membrane structure and chemistry on polyamide-polysulfone interfacial composite membranes. J. Membr. Sci. 2009, 336 (1-2), 140-148.

(32) Lind, M. L.; Ghosh, A. K.; Jawor, A.; Huang, X. F.; Hou, W.; Yang, Y.; Hoek, E. M. V. Influence of zeolite crystal size on zeolite-polyamide thin film nanocomposite membranes. Langmuir 2009, 25 (17), 10139-10145.

(33) Kawaguchi, T.; Tamura, H. Chlorine-resistant membrane for reverse-osmosis. 1. Correlation between chemical structures and chlorine resistance of polyamides. J. Appl. Polym. Sci. 1984, 29 (11), 3359-3367.

(34) Glater, J.; Zachariah, M. R. A Mechanistic study of halogen interaction with polyamide reverse-osmosis membranes. ACS Symp. Ser. 1985, 281, 345-358.

(35) Mehta, G. D.; Loeb, S. Internal polarization in the porous substructure of a semipermeable membrane under pressure-retarded osmosis. J. Membr. Sci. 1978, 4 (2), 261-265.

(36) Loeb, S.; Titelman, L.; Korngold, E.; Freiman, J. Effect of porous support fabric on osmosis through a Loeb-Sourirajan type asymmetric membrane. J. Membr. Sci. 1997, 129 (2), 243-249.

(37) Robeson, L. M. Correlation of separation factor versus permeability for polymeric membranes. J. Membr. Sci. 1991, 62 (2), $165-185$.

(38) Mehta, A.; Zydney, A. L. Permeability and selectivity analysis for ultrafiltration membranes. J. Membr. Sci. 2005, 249 (1-2), 245-249. 